\title{
Decreased expression of KAI1/CD82 metastasis suppressor gene is associated with loss of heterozygosity in melanoma cell lines
}

\author{
YOUNG IL KIM ${ }^{1}$, MIN-KYUNG SHIN ${ }^{2}$, JIN-WOO LEE ${ }^{1}$, JOO-HO CHUNG ${ }^{3}$ and MU-HYOUNG LEE ${ }^{2}$ \\ ${ }^{1}$ East-West Medical Research Institute, Kyunghee University; ${ }^{2}$ Department of Dermatology, Kyunghee University, \\ College of Medicine; ${ }^{3}$ Department of Pharmacology, Kyunghee University, College of Medicine, Seoul 130-702, Korea
}

Received July 19, 2008; Accepted October 20, 2008

DOI: $10.3892 /$ or_00000203

\begin{abstract}
KAI1/CD82, a metastasis suppressor gene of prostate cancer, is located on the human chromosome 11p11.2. Down-regulation of KAI1/CD82 during tumor progression and metastasis has been reported in several cancers, but the mechanism of this down-regulation remains unknown. The relationship between down-regulation of KAI1/CD82 mRNA expression and KAI1/CD82 gene alterations in human melanoma cell lines were investigated. The promoter methylation status was examined after a 331-bp GC-rich fragment of the promoter region was amplified in G361, SK-MEL-24 and SK-MEL-28 cell lines treated with bisulfite. In order to detect methylated $\mathrm{CpGs}$ in all three cell lines, 331-bp fragments were sequenced. To examine the restoration of KAI1/CD82 mRNA and protein expression, the cells were exposed to methylase inhibitor, 5-aza-2'deoxycytidine (5-AzaC). Bisulfite-sequencing data showed no methylation in G361 and SK-MEL-24 cells, and slight methylation in SK-MEL-28 cells at CpG sites 23-26 in the promoter. Real-time PCR and flow cytometry analysis showed that 5-AzaC-treated cells restored KAI1/CD82 mRNA and protein expression in SK-MEL-24 and SK-MEL28 cells, compared to the controls. The restoration of KAI1/ CD82 mRNA and protein expression detected no significant difference between SK-MEL-24 and SK-MEL-28 cells. This means that 5-AzaC did not affect the methylated cells only. Loss of heterozygosity ( $\mathrm{LOH})$ at polymorphic microsatellite loci on the human chromosome 11 in the human melanoma cells was also examined. Microsatellite analysis showed LOH at D11S1344 in SK-MEL-24 and SK-MEL-28 cells, and G361 showed allelic imbalance. In conclusion, this study suggests that down-regulation of KAI1/CD82 mRNA
\end{abstract}

Correspondence to: Dr Mu-Hyoung Lee, Department of Dermatology, Kyunghee University, College of Medicine, 1 Hoekidong, Dongdaemun-ku, Seoul 130-702, Korea

E-mail:mhlee@khmc.or.kr

Key words: melanocyte, melanoma cells, methylation, KAI1/ CD82, loss of heterozygosity, 5-aza-2'-deoxycytidine, real-time PCR, flow cytometry expression in human melanoma cell lines is related to $\mathrm{LOH}$ or allelic imbalance, but not to methylation of the KAI1/ CD82 gene region.

\section{Introduction}

The KAI1 gene, originally identified as a putative metastasis suppressor gene for prostate cancer, maps to the human chromosome 11 p11.2(1). It encodes a 267 amino acid protein with four membrane-spanning segments and a single major extracellular domain, with three potential N-glycosylation sites belonging to the transmembrane 4 superfamily (2). KAI1 was revealed to be the same gene as R2, C33, IA4 and 4F9 (3), which have been isolated from the cDNA libraries of human leukocytes and classified as CD82.

Down-regulation of KAI1/CD 82 mRNA and protein levels has been reported in the invasive and metastatic stages of various cancers including prostate cancer $(4,5)$. KAI1/ CD82 might function as a negative regulator of colorectal carcinoma metastasis (6), and suppress integrin-induced invasion by regulating signaling to c-Met and Src kinases (7). Expression of KAI1/CD82 has been reported to reduce cell motility and invasiveness in vivo in melanoma cells (8). Thus, down-regulation of KAI1/CD82 expression may be an important step in the progression of many types of human malignancy, but the mechanism of the down-regulation remains to be elucidated.

Epigenetics are heritable attributes that influence gene activity without changing the DNA sequence. The major forms of epigenetics modification occurring in human tumors are DNA methylation and histone deacetylation. Methylation can directly switch off gene expression by preventing transcription factors binding to the promoters. $\mathrm{CpG}$ island methylation is an epigenetic alteration that contributes to tumorigenesis by inactivating gene transcription (9). The $\mathrm{KAI} 1 / \mathrm{CD} 82$ promoter sequence is $68 \%$ GC-rich overall, with a core region of $80 \%$ GC (10), defining a CpG island within a 1036-bp region extending from the $5^{\prime}$ promoter through the transcription initiation site into intron 1 (11). Loss of heterozygosity ( $\mathrm{LOH})$ is a common indicator for the involvement of tumor suppressor gene in the pathogenesis of carcinomas and $\mathrm{LOH}$ of $11 \mathrm{p} 11.2$ has been reported in advanced human prostate cancer (12). The methylation status of the KAI1/CD82 5' regulatory region and $\mathrm{LOH}$ were examined to clarify these relations in down-regulation of 
KAI1/CD82 expression in human melanoma cell lines. The restoration of KAI1/CD82 mRNA and protein expression in cell lines was also investigated after treatment with the demethylating agent 5-aza-2'-deoxycytidine (5-AzaC).

\section{Materials and methods}

Cell culture. Normal human melanocytes were obtained from neonatal foreskin. In brief, the epidermis was separated from the dermis by treatment overnight with $0.05 \%$ trypsin at $4^{\circ} \mathrm{C}$, and then an epidermal cell suspension was prepared. The melanocytes were grown in Medium 254 (Cascade Biologics Inc., Portland, OR, USA) with $2 \%$ fetal bovine serum (FBS, Hyclone, Logan, UT, USA), $10 \mathrm{nM}$ endothelin-1 (Peninsula Laboratories, Belmont, CA, USA), $12 \mathrm{nM} \alpha$-MSH (Sigma Chemical Co., St. Louis, MO, USA), $10 \mathrm{nM}$ basic FGF (R\&D Systems, Minneapolis, MN, USA), and $1 \%$ penicillinstreptomycin-amphotericin B $(10,000 \mathrm{U} / \mathrm{ml}, 10,000 \mu \mathrm{g} / \mathrm{ml}$, and $25 \mu \mathrm{g} / \mathrm{ml}$, respectively; Gibco-BRL, Carlsbad, CA, USA) in a $37^{\circ} \mathrm{C}$ humidified atmosphere containing $5 \% \mathrm{CO}_{2}$ (13). The melanocytes were then selectively harvested by differential trypsinization. Third-passaged cells were used in this study.

Human melanoma cell lines G361, SK-MEL-24 and SKMEL-28 were purchased from the American Tissue Culture Collection (Rockville, MD, USA). G361 and SK-MEL-28 were derived from primary melanoma of the skin. SK-MEL24 was derived from metastatic site, lymph node. G361 cells were cultured in RPMI-1640 medium, and SK-MEL-24 and SK-MEL-28 cells were cultured in Dulbecco's modified Eagle's medium (DMEM, Gibco, Grand Island, NY, USA) containing $10 \% \mathrm{FBS}, 100 \mathrm{U} / \mathrm{ml}$ penicillin, and $100 \mu \mathrm{g} / \mathrm{ml}$ streptomycin at $37^{\circ} \mathrm{C}$ in a humidified atmosphere of $5 \% \mathrm{CO}_{2}$ and $95 \%$ air.

RT-PCR and real-time PCR analysis. Total RNA was purified from cultured cells using the RNA-Bee solution kit (Tel-test, Friendswood, TX, USA). First-strand cDNA synthesis was performed with $1 \mu \mathrm{g}$ of the total RNA and transcribed to cDNA using reverse transcription system (Promega, Madison, WI, USA) according to the manufacturer's protocol random hexamers. The polymerase chain reaction (PCR) was performed with $2 \mu \mathrm{l}$ of cDNA in a $50 \mu 1$ reaction mixture of $1 \mathrm{X}$ PCR buffer, $200 \mu \mathrm{M}$ of each dNTP, 20 pmol each primer, and 1 unit of AmpliTaq Gold DNA polymerase (Roche, Applied Biosystems, Foster City, CA, USA). The conditions for amplification were: first denaturation at $95^{\circ} \mathrm{C}$ for $14 \mathrm{~min}$, then denaturation at $95^{\circ} \mathrm{C}$ for $1 \mathrm{~min}$, annealing at $55^{\circ} \mathrm{C}$ for $1 \mathrm{~min}$, and extension at $72^{\circ} \mathrm{C}$ for $1 \mathrm{~min}$ for 22 (B-actin) to 30 (KAI1/CD82) cycles and final extension at $72^{\circ} \mathrm{C}$ for $10 \mathrm{~min}$. PCR product $(10 \mu \mathrm{l})$ was separated by electrophoresis on a $2 \%$ agarose gel containing ethidium bromide and visualized by image analysis. The primer sequences for KAI1/CD82 RT-PCR and real-time PCR were 5'-CATGAATCGCCCTGAGGTCAC CTA-3' and 5'-GCCTGCACCTTCTCCATGCAGCCC-3' and the sequences for 3 -actin were 5'-CTTCTACAATGAGCT GCGTG-3' and 5'-TCATGAGGTAGTCAGTCAGG-3', with expected product sizes of 174 and $305 \mathrm{bp}$, respectively. Real-time PCR was performed on a LightCycler (Roche

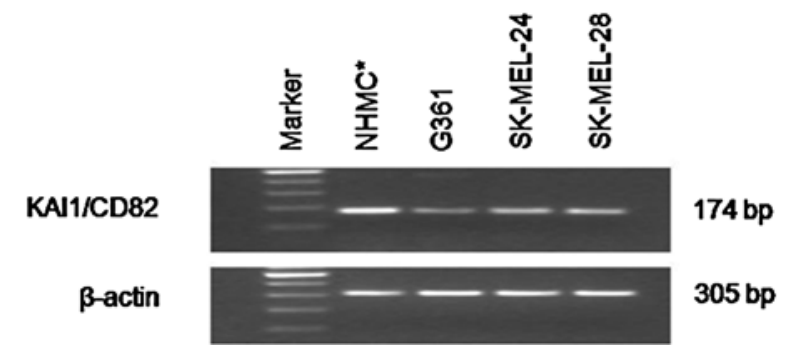

Figure 1. RT-PCR analysis of KAI1/CD82 mRNA expression in normal human melanocytes and human melanoma cell lines. mRNA levels were measured by RT-PCR. PCR products were separated on a $2 \%$ agarose gel and stained with ethidium bromide. "NHMC, normal human melanocyte.

Diagnostics, Lewes, UK) with the LightCycler ${ }^{\circledR}$ FastStart DNA Master SYBR Green I (Roche Diagnostics). A final reaction volume of $20 \mu \mathrm{l}$ contained $2 \mu \mathrm{l}$ of cDNA, $2 \mu \mathrm{l}$ of SYBR green Mastermix, $2.4 \mu \mathrm{l}$ of $25 \mathrm{mM} \mathrm{MgCl}_{2}, 2 \mu \mathrm{l}$ of each primer and $11.6 \mu 1$ of PCR grade water. The reaction was performed using primers with a denaturation step of $94^{\circ} \mathrm{C}$ for $10 \mathrm{~min}$ followed by 40 cycles at $94^{\circ} \mathrm{C}$ for $10 \mathrm{sec}$, $55^{\circ} \mathrm{C}$ (ß-actin) to $62^{\circ} \mathrm{C}$ (KAI1/CD82) for $15 \mathrm{sec}$. Normalized gene expression was calculated as the ratio between KAI1/ CD82 and ß-actin copy number.

Bisulfite modification. The methylation status of $\mathrm{CpG}$ islands within the KAI1/CD82 promoter in all sample DNAs was analyzed by methylation-specific PCR on the sodium bisulfite-converted DNA (14). Genomic DNA was extracted using a Wizard Genomic DNA purification kit (Promega). DNA $(4 \mu \mathrm{g})$ in a volume of $50 \mu \mathrm{l}$ was denatured with $\mathrm{NaOH}$ (final concentration, $0.2 \mathrm{M}$ ) and incubated at $37^{\circ} \mathrm{C}$ for $15 \mathrm{~min}$. Thirty microliters of $10 \mathrm{mM}$ hydroquinone and $520 \mu 13 \mathrm{M}$ sodium bisulfite (Sigma-Aldrich Co.) at pH 5.0, both freshly prepared, were added to the DNA and mixed. Samples were incubated under mineral oil at $55^{\circ} \mathrm{C}$ for $16 \mathrm{~h}$. After the reaction, the DNA was desalted with a Wizard DNA CleanUp system (Promega), desulfonated by addition of $\mathrm{NaOH}$ (final concentration, $0.3 \mathrm{M}$ ), and incubated at $37^{\circ} \mathrm{C}$ for $15 \mathrm{~min}$. The DNA was ethanol-precipitated, dried, re-suspended in $20 \mu \mathrm{l}$ of water, and used immediately or stored at $-20^{\circ} \mathrm{C}$.

Methylation assay for the KAI1/CD82 gene promoter region. Primers were designed to discriminate between methylated and unmethylated alleles following bisulfite treatment, and to discriminate between DNA modified by bisulfite treatment and DNA that was not modified. First, bisulfite-treated DNA was amplified using a sense primer (5'-AGGGTA GGGTAGGATTAGGAA-3'; KAI1-1S: -494 to -474) and an antisense primer (5'-CTCCTTTTCACCCACCAACTACT-3'; KAI1-1AS: +206 to +228$)$. The $50 \mu 1$ PCR reactions contained $200 \mathrm{ng}$ of bisulfite-treated DNA, 20 pmol of each specific primer, $200 \mu \mathrm{M}$ dNTPs, 1X PCR buffer $[10 \mathrm{mM}$ Tris/ $\mathrm{HCl}$ (pH 8.3), $50 \mathrm{mM} \mathrm{KCl}$, and $1.5 \mathrm{mM} \mathrm{MgCl}_{2}$ ], and 1 Unit AmpliTaq Gold DNA polymerase (Roche, Applied Biosystems). The amplification conditions consisted of 35 cycles of $94^{\circ} \mathrm{C}$ for $30 \mathrm{sec}, 50^{\circ} \mathrm{C}$ for $60 \mathrm{sec}$, and $72^{\circ} \mathrm{C}$ for $60 \mathrm{sec}$ followed by a final extension step $\left(72^{\circ} \mathrm{C}\right.$ for $\left.5 \mathrm{~min}\right)$. Next, a 331-bp fragment was amplified using $2 \mu \mathrm{l}$ of the first-round 
A

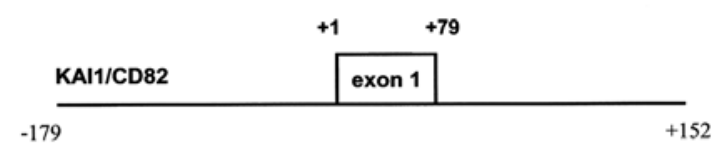

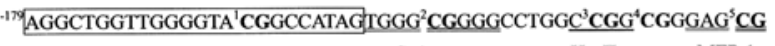

$$
\begin{aligned}
& \text { Spl Hpall MEP-1 } \\
& \text { CAC }^{6} \text { CGCCTTCCCAAAGGGCT }^{7} \text { CGGGG }^{8} \text { CGGGGC }^{9} \text { CGG }^{10} \text { CGGAGGGGG }^{11} \text { CGTGTC }^{-1} \\
& \text { NF-IL6, TCF-1 Sp1 HpaII }
\end{aligned}
$$

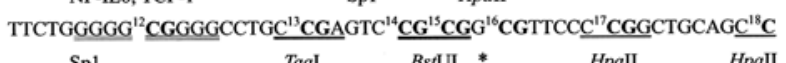

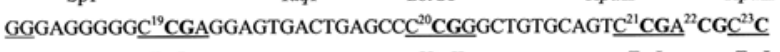

$$
\begin{aligned}
& \text { TaqI Hpall }
\end{aligned}
$$

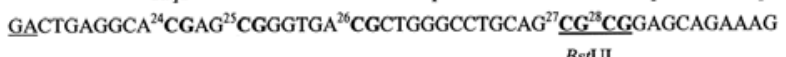

$$
\begin{aligned}
& B s t \mathrm{UI} \\
& \text { CAGAACC }^{20} \mathrm{CGCAGGTGAGCAAGGGGCAG}^{30} \mathrm{CGGGC}^{31} \mathrm{CGGGGTAGCTG}^{{ }^{32} \mathrm{CGGA}^{-}} \\
& \text {EcoRI } \\
& \text { HpaII } \\
& \text { HpaII } \\
& \text { CAACCATA GGCAAAGTTAGTTTTAGCCCC }{ }^{31} \mathrm{CGCTTO}^{-152}
\end{aligned}
$$

C

CpG sites

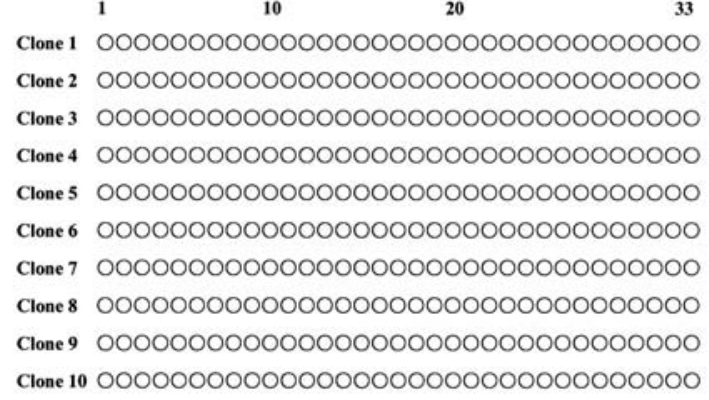

Clone 1 OOO000000000000000000000000000000 Clone 2 $0000000000000000000000 \bullet 0000000000$

Clone 3000000000000000000000000000000000

Clone 4000000000000000000000000000000000

Clone 5000000000000000000000000000000000

SK-MEL-24 Clone 5 O00000000000000000000000000000000

Clone 7000000000000000000000000000000000

Clone 8 000000000000000000000000000000000

Clone 9000000000000000000000000000000000 Clone 10000000000000000000000000000000000

Clone 1 000000000000000000000000000000000 Clone 2000000000000000000000000000000000 Clone 3000000000000000000000000000000000

Clone 4000000000000000000000000000000000 Clone $50000000000000000000000 \bullet \bullet \bullet \bullet 0000000$

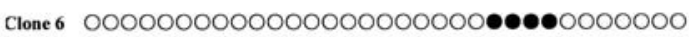
Clone 7 000000000000000000000000000000000 Clone $80000000 \bullet 0000000000000000000000000$

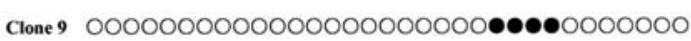
Clone $10000000000000000000000000 \bullet 00000000$

reaction mixture under similar conditions, except that annealing was performed at $55^{\circ} \mathrm{C}$, with the following primers. The nested primers used were 5'-AGGTTGGTTGGGGTAY GGTTAT-3' (KAI1-2S: Y=C or T; -179 to -156$)$ and 5'-AAA ACXAAAACTAAAACTAACTTTACC-3' (KAI1-2AS, $\mathrm{X}=\mathrm{A}$ or $\mathrm{G} ;+126$ to +152 ). The locations of the primers were determined based on the published KAI1/CD82 promoter sequence (15). After ethanol precipitation, the PCR products were digested with BstUI, EcoRI, HpaII, and TaqI enzymes (New England Biolabs, Beverly, MA, USA). The

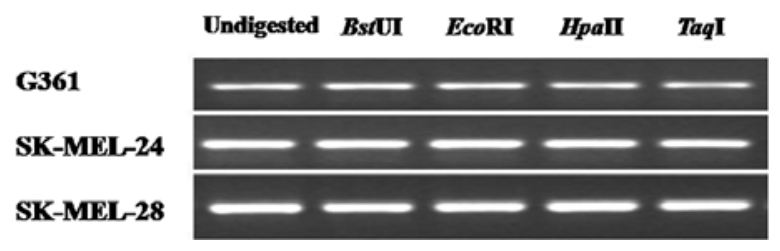

D
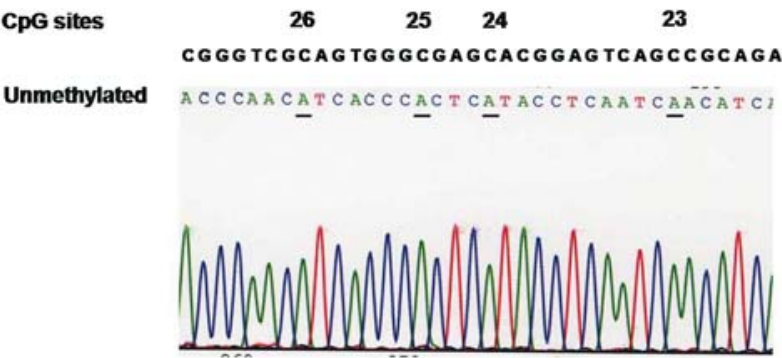

Methylated

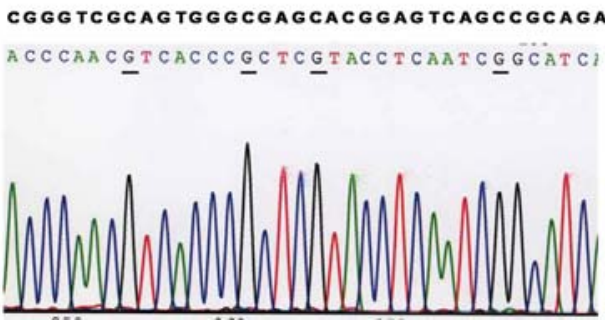

Figure 2. Methylation analysis of the KAI1/CD82 promoter region in human melanoma cell lines. (A) Schematic illustration of the KAI1/CD82 promoter region around the transcription start site between residues -735 and +351 , as previously defined by Dong et al (10). The 331-bp fragments amplified for methylation analysis are shown in the outlined panels. Within these fragments, $\mathrm{CpG}$ pairs are shown in bold type and numbered from 1 to 33 based on their position relative to the transcription start site $(*)$. Recognition sequences for restriction enzymes BstU1 (CGCG), EcoRI (GAACCC), HpaII (CCGG), and TaqI (CCGA) are underlined. Putative binding sites for transcription factors are indicated by double underlining, and primer sequences are boxed. (B) Restriction enzyme analysis of the bisulfite-treated KAI1/CD82 promoter region in DNAs from three melanoma cell lines. (C) Methylation profile of the core KAI1/CD82 promoter region in melanoma cells. Methylation levels were determined by sequencing of 10 independent clones derived from amplified bisulfite-treated DNA isolated from melanoma cell lines. Unmethylated and methylated $\mathrm{CpG}$ dinucleotides are represented by open $(\odot)$ and closed circles $(\bullet)$, respectively. (D) Sequence analysis of the 331-bp fragment from one of the SK-MEL-28 clones using antisense primers showed methylation at $\mathrm{CpG}$ sites 23-26.

PCR products were then separated on a $2 \%$ agarose gel and visualized by ethidium bromide. For further analysis of representative samples, the 331-bp PCR products were gelpurified, ligated into the pCR2.1 cloning vector, and cloned using the TA Cloning kit according to the manufacturer's instructions (Invitrogen, Carlsbad, CA, USA). Ten clones of each product were sequenced, and the methylation rates of individual CpGs (sites 1-33) in the cells were calculated.

Flow cytometric analysis. The cultured cells were detached with $0.05 \%$ trypsin-EDTA solution. After washing with cold PBS, cells were then incubated with a 1:50 dilution of antiKAI1/CD82 rabbit polyclonal antibody (Santa Cruz 


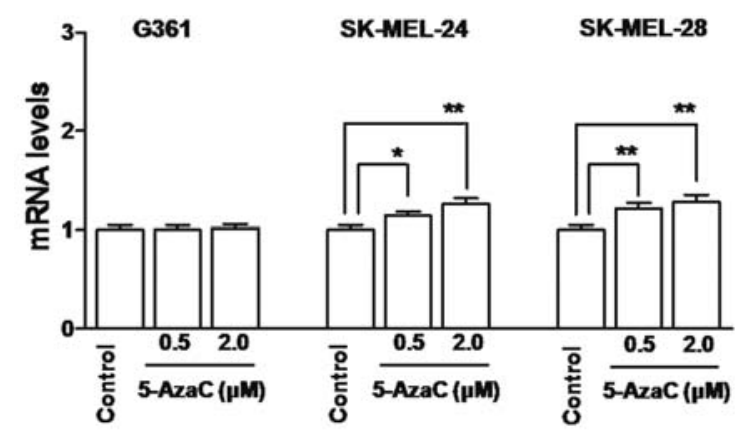

Figure 3. Real-time PCR analysis of KAI1/CD82 mRNA expression in human melanoma cell lines. Cells were treated with 5 -AzaC $(0.5$ or $2.0 \mu \mathrm{M})$ for 5 days with replacement of the medium and the drug every $48 \mathrm{~h}$. Then, mRNA levels were measured by real-time PCR. Values are mean \pm SD of three independent experiments, and reported as the ratio of KAI1/CD82 to ß-actin copy number. ${ }^{*} \mathrm{P}<0.05$ and ${ }^{* *} \mathrm{P}<0.01$ compared to control.

Biotechnology, Santa Cruz, CA, USA) or normal rabbit serum as a negative control for $30 \mathrm{~min}$ at $4^{\circ} \mathrm{C}$. After being washed 3 times with cold PBS, cells were stained with fluoresceine isothiocyanate (FITC)-labeled goat antibody to 1:50 diluted rabbit immunoglobulin for $30 \mathrm{~min}$ at $4^{\circ} \mathrm{C}$. Washing was repeated in the same manner and cell surface immunofluorescence was analyzed using a FACSCalibur with CellQuest software (Becton Dickinson, San Jose, CA, USA).

Microsatellite analysis of loss of heterozygosity $(\mathrm{LOH}) . \mathrm{LOH}$ was determined using microsatellite markers on $11 \mathrm{p} 11.2$ that was previously described (16). The primer sequences used were 5'-TGCCAAGAACAGCAAAA-3' (CA strand) and 5'-GGGGTTCAAAATAAACAAAA-3 (GT strand) for D11S1326 and 5'-CCCTGAACTTCTGCATTCAC-3' (CA strand) and 5'-GCGCCTGGCTTGTACATATA-3' (GT strand) for 11D1344. PCR was performed in $20 \mu 1$ reactions consisting of $200 \mathrm{ng}$ of DNA, 1X PCR buffer, $0.2 \mathrm{mM}$ dNTPs, 10 pmol of each primer, and 1 Unit AmpliTaq Gold DNA polymerase. The condition for amplification were as follows: after denaturation at $95^{\circ} \mathrm{C}$ for $14 \mathrm{~min}$, then denaturation at $95^{\circ} \mathrm{C}$ for $1 \mathrm{~min}$, annealing at $52^{\circ} \mathrm{C}$ for $1 \mathrm{~min}$, and extension at $72^{\circ} \mathrm{C}$ for $1 \mathrm{~min}$ for 30 cycles and final extension at $72^{\circ} \mathrm{C}$ for $10 \mathrm{~min}$. PCR products $(2 \mu \mathrm{l})$ were mixed with $18 \mu 1$ of stop solution containing $95 \%$ formamide, $10 \mathrm{mM} \mathrm{NaOH}, 0.25 \%$ bromophenol blue, and $0.25 \%$ xylene cyanol FF. The mixture was denatured at $95^{\circ} \mathrm{C}$ for $5 \mathrm{~min}$, put onto ice for $5 \mathrm{~min}$ and electrophoresed on $12 \%$ polyacrylamide gels containing $10 \%$ glycerol with $1 \mathrm{X}$ TBE buffer, and stained with ethidium bromide and visualized by image analysis.

Statistical analysis. Student's t-test was used to evaluate differences between control samples and 5-AzaC-treated samples. Differences were considered statistically significant at ${ }^{*} \mathrm{P}<0.05$ and ${ }^{* *} \mathrm{P}<0.01$.

\section{Results}

Expression of KAI1/CD82 mRNA in melanoma cells. The expression of KAI1/CD82 mRNA decreased in human
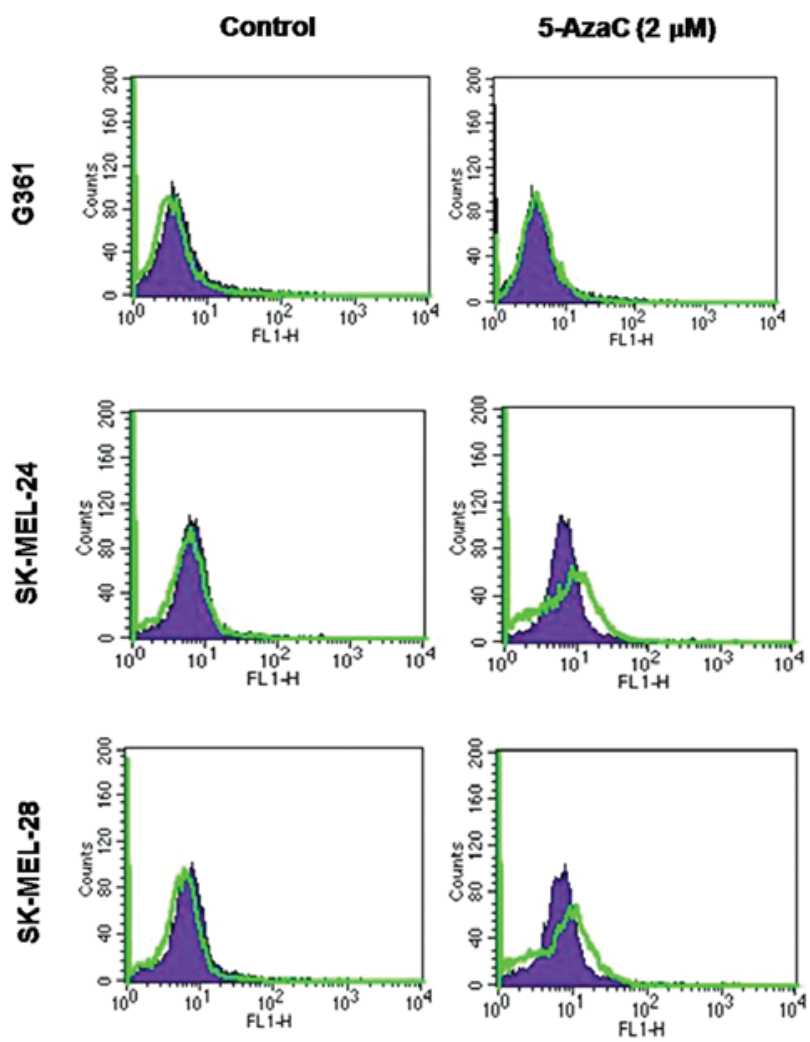

Figure 4. Expression of the KAI1/CD82 protein in human melanoma cell lines. Cells were treated with $2.0 \mu \mathrm{M} 5$-AzaC for 5 days with replacement of the medium and the drug every $48 \mathrm{~h}$. Then, KAI1/CD82 protein levels were measured by flow cytometry. The reactivity of these cells with an antiKAI1/CD82 rabbit polyclonal antibody is shown (green). Diluted normal rabbit serum was used as negative control for the primary antibody (blue).

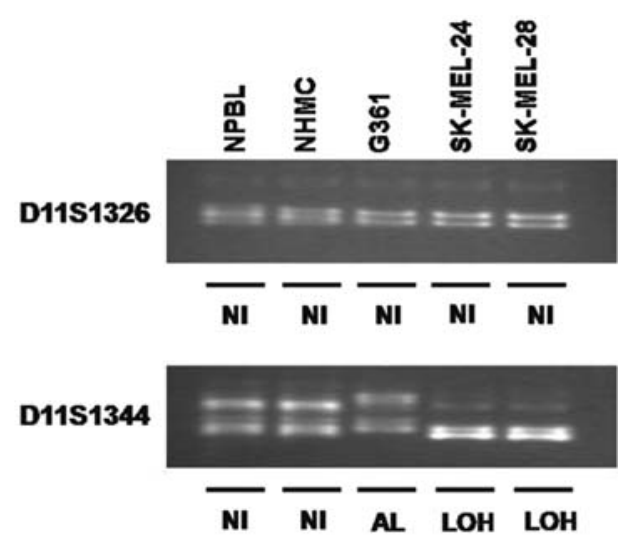

Figure 5. Microsatellite analysis at D11S1326 and D11S1344 locus in human melanoma cell lines. Genomic DNA was amplified using PCR for detection in 11q11.2 chromosomal region. PCR products were detected by $12 \%$ polyacrylamide gels, stained with ethidium bromide and photographed. NPBL, normal peripheral leukocytes; NHMC, normal human melanocytes; NI, not informative; AL, allelic imbalance; LOH, loss of heterozygosity.

melanoma cell lines when compared to normal melanocyte (Fig. 1).

Methylation assay of the KAII/CD82 gene promoter region. To determine whether methylation in the promoter region was heterogeneous, we amplified 331-bp fragments of each 
DNA after bisulfite treatment. The 331-bp fragment, which represents the most GC-rich area within the 5' regulatory region of $\mathrm{KAI} 1 / \mathrm{CD} 82$, contains $33 \mathrm{CpG}$ dinucleotides, as well as the transcription initiation site and several putative binding sites for transcription factors (Fig. 2A). We digested the 331-bp PCR fragments with BstUI, EcoRI, HpaII, and TaqI; however, no digestion products were observed in any bisulfite-treated cell lines (Fig. 2B). When we sequenced the 331-bp fragments, no methylation was detected in the G361 or SK-MEL-24 cell lines (Fig. 2C), and a few methylation of CpG sites 23-26 in the SK-MEL-28 cell line (Fig. 2C and D) was observed.

Restored expression of KAII/CD82 mRNA. To assess restoration of KAI1/CD82 mRNA expression, cells were exposed to various concentrations of the methylase inhibitor 5-AzaC. After the melanoma cells were exposed to $2.0 \mu \mathrm{M}$ 5 -AzaC, the levels of KAI1/CD82 mRNA increased in SKMEL-24 and SK-MEL-28, but not in G361 when compared to each control (Fig. $3,{ }^{*} \mathrm{P}<0.05$ and ${ }^{* *} \mathrm{P}<0.01$ ). There was no significant difference of the levels of KAI1/CD82 mRNA between SK-MEL-24 and SK-MEL-28 cells.

Cell surface expression of KAII/CD82 protein. To examine the expression KAI1/CD82 gene at the protein level, cells were treated with $2.0 \mu \mathrm{M} 5$-AzaC for 5 days. KAI1/CD82 protein level was performed using flow cytometry. After 5 -AazC treatment, reproduction of protein levels increased in both SK-MEL-24 and SK-MEL-28 cells, but not in G361 (Fig. 4). There was no significant difference of the levels of KAI1/CD82 protein between SK-MEL-24 and SK-MEL-28.

LOH analysis. $\mathrm{LOH}$ at $11 \mathrm{q} 11.2$ the chromosomal region harboring the KAI1/CD82 gene was observed LOH at 11DS1344 in SK-MEL-24 and SK-MEL-28 cells, whereas G361 cells showed allelic imbalance. $\mathrm{LOH}$ at 11D1326 was not detected.

\section{Discussion}

$\mathrm{KAI} 1 / \mathrm{CD} 82$ is widely expressed in human tissues, and downregulation of this gene is associated with the metastatic phenotype of several malignancies, including carcinomas of the prostate, lung, colon, pancreas, stomach, liver and bladder. Down-regulation of KAI1/CD82 is associated with the acquisition of high metastatic ability in Dunning rat prostate cancers (17). The transfer of the KAI1/CD82 gene into mammary cancer cells suppresses their metastatic potential but does not affect primary tumor growth $(8,18)$. A previous study showed that the expression of KAI1/CD82 increased in human melanoma cell lines when compared to human prostate cancer cell lines, and lung cancer cell lines (19). In this study, the expression of KAI1/CD82 mRNA decreased in human melanoma cell lines, compared to normal melanocytes. Using methylation analysis of DNA isolated from human melanoma cells, we found no methylation in either G361 or SK-MEL-24 cells and slight methylation of $\mathrm{CpG}$ islands (CpG 23-26) within the KAI1 promoter region in SK-MEL-28 cells. SK-MEL-24 cells were expected to have the most malignant potency among the three melanoma cell lines, because the cell line originated from metastatic melanoma cells. Interestingly, the results of the expression of KAI1/CD82 and methylation status showed little relation with it.

The results of treatment with 5-AzaC differ depending on the type of cancer. Treatment with 5-AzaC does not activate KAI1/CD82 mRNA expression in invasive bladder tumors or in cell lines derived from such tumors (20). In PC-3 and DU145 prostate cancer cells, treatment with 5-AzaC and trichostatin A restores expression of KAI1 mRNA in spite of unmethylation of KAI1/CD82 promoter region (15). Zhu et al reported 5-AzaC not only increases the expression of methylated gene but also unmethylated gene (21). In this study, 5-AzaC treatment restored expression of KAI1/CD82 mRNA and protein in the two SK-MEL-24 cells with no methylation and SK-MEL-28 cells with a few methylation. This result suggests that 5 -AzaC treatment does not affect only the methylated cells.

The involvement of KAI1/CD82 gene alterations in prostatic cancer showed $\mathrm{LOH}$ at D11S1344 $(5,12)$. In this study, $\mathrm{LOH}$ at 11q11.2 the chromosomal region harboring the KAI1/CD82 gene was observed LOH at 11DS1344 in SK-MEL-24 and SK-MEL-28 cell lines and G361 cells showed allelic imbalance. This result suggests that downregulation of KAI1 mRNA expression might be related to LOH in human melanoma cell lines.

Consequently, this study suggests that down-regulation of KAI1/CD82 mRNA expression is associated with LOH or allelic imbalances but not with methylation of KAI1/CD82 gene in human melanoma cell lines.

\section{Acknowledgements}

This study was supported by Kyunghee University (Seoul, Korea) Research Fund in 2005 (KHU-20050422).

\section{References}

1. Dong JT, Lamb PW, Rinker-Schaeffer CW, Vukanovic J, Ichikawa T, Isaacs JT and Barrett JC: KAI1, a metastasis suppressor gene for prostate cancer on human chromosome 11p11.2. Science 268: 884-886, 1995

2. Wright MD and Tomlinson MG: The ins and outs of transmembrane 4 superfamily. Immunol Today 15: 588-594, 1994.

3. Nojima Y, Hirose T, Tachibana K, et al: The 4F9 antigen is a member of the tetra spans transmembrane protein family and functions as an accessory molecule in $\mathrm{T}$ cell activation and adhesion. Cell Immunol 152: 249-260, 1993.

4. Dong JT, Suzuki H, Pin SS, et al: Down-regulation of the KAI1 metastasis suppressor gene during the progression of human prostatic cancer infrequently involves gene mutation or allelic loss. Cancer Res 56: 4387-4390, 1996.

5. Ueda T, Ichikawa T, Tamaru J, et al: Expression of the KAI1 protein in benign prostatic hyperplasia and prostate cancer. Am J Pathol 149: 1435-1440, 1996.

6. Liu L, Wu DH, Li ZG, et al: Effects of KAI1/CD82 on biological behavior of human colorectal carcinoma cell line. World J Gastroenterol 9: 1231-1236, 2003.

7. Sridhar SC and Miranti CK: Tetraspanin KAI1/CD82 suppresses invasion by inhibiting integrin-dependent cross talk with c-Met receptor and Src kinases. Oncogene 25: 2367-2378, 2006.

8. Takaoka A, Hinoda Y, Sato S, Itoh F, Adachi M, Hareyama M and Imai K: Reduced invasive and metastatic potentials of KAI1-transfected melanoma cells. Jpn J Cancer Res 89: 397-404, 1998.

9. Jones PA and Baylin SB: The fundamental role of epigenetic events in cancer. Nat Rev Genet 3: 415-428, 2002. 
10. Dong JT, Issacs WB, Barrett JC and Issacs JT: Genomic organization of the human KAI1 metastasis-suppressor gene. Genomics 41: 25-32, 1997.

11. Gardiner-Garden $\mathrm{M}$ and Frommer $\mathrm{M}$ : $\mathrm{CpG}$ islands in vertebrate genomes. J Mol Biol 196: 261-282, 1987.

12. Kawana Y, Komiya A, Ueda T, et al: Location of KAI1 on the short arm of human chromosome 11 and frequency of allelic loss in advanced human prostate cancer. Prostate 32: 205-213, 1997.

13. Lee MH, Ryu JH and Juhn BJ: Comparison of the human melanocyte culture in phorbol 12-myristate 13-acetatecontained medium and physiologic mitogens-contained medium. Korean J Dermatol 37: 168-176, 1999.

14. Clark SJ, Harrison J, Paul CL and Frommer M: High sensitivity mapping of methylated cytosines. Nucleic Acids Res 22: 2990-2997, 1994.

15. Sekita N, Suzuki H, Ichikawa T, et al: Epigenetic regulation of the KAI1 metastasis suppressor gene in human prostate cancer cell lines. Jpn J Cancer Res 92: 947-951, 2001.

16. Tagawa K, Arihiro K, Takeshima Y, Hiyama E, Yamasaki M and Inai K: Down-regulation of KAI1 messenger RNA expression is not associated with loss of heterozygosity of the KAI1 gene region in lung adenocarcinoma. Jpn J Cancer Res 90: 970-976, 1999.
17. Suzuki H, Dong JT, Gao AC, Barrett JC and Issacs JT: Identification of the rat homologue of KAI1 and its expression in Dunning rat prostate cancers. Prostate 37: 253-260, 1998.

18. Yang X, Wei LL, Tang C, Slack R, Mueller S and Lippman ME: Overexpression of KAI1 suppresses in vitro invasiveness and in vivo metastasis in breast cancer cells. Cancer Res 61: 5284-5288, 2001.

19. Li S, Fang W and Zhong H: Expression of tumor metastasis suppressor gene KAI1/CD82 in human cancer cell lines with different metastasis potential. Zhonghua Yi Xue Zhi 79: 708-710, 1999.

20. Jackson P, Millar D, Kingsley E, Yardley G, Ow K, Clark S and Russell PJ: Methylation of a $\mathrm{CpG}$ island within the promoter region of the KAI1 metastasis suppressor gene is not responsible for down-regulation of KAI1 expression in invasive cancers or cancer cell lines. Cancer Lett 157: 169-176, 2000.

21. Zhu WG, Dai Z, Ding H, et al: Increased expression of unmethylated CDK2D by 5-aza-2'-deoxycytidine in human lung cancer cells. Oncogene 20: 7787-7796, 2001. 